International Journal of

Health, Medicine and

Nursing Practice

(IJHMNP)

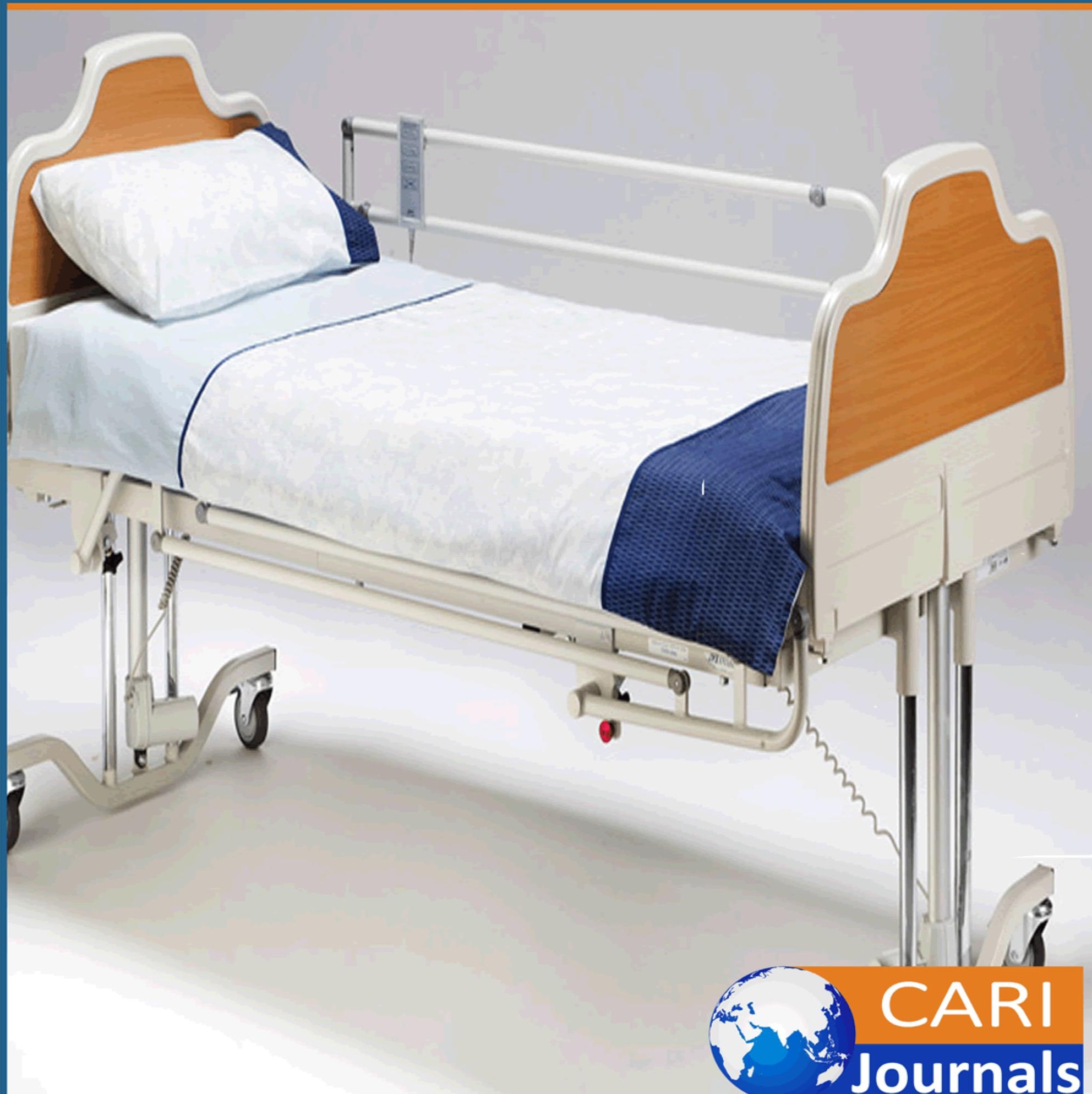




\title{
The Influence of Product Design Attributes on The Usage of Insecticide Treated Mosquito Nets in Kafue District, Zambia
}

\author{
1*Timothy Silweya \\ ${ }^{1}$ Post Graduate Student: Graduate School of Business, University of Zambia \\ *Corresponding Author's E-mail: timosilweya@yahoo.co.uk \\ ${ }^{2}$ Dr. Charles Muwe Mungule \\ Lecturer: Graduate School of Business, University of Zambia \\ *Corresponding Author's E-mail: muwendaza@hotmail.co.za
}

\begin{abstract}
Purpose: The purpose of this study was to investigate the relationship between colour, shape and size of Insecticide Treated Nets (ITNs) and use.

Methodology: This study used mixed methods research design. The research was conducted in Kafue district at Nangongwe and Kafue Mission Health Centre catchment areas. A simple random sampling approach was used to select 30 households (HHs) from a total of $300 \mathrm{HHs}$ that had ITNs. Due to heavy rains, one $\mathrm{HH}$ was not reached hence sample size reduced to $29 \mathrm{HHs}$. Questionnaires were used to collect quantitative data while Focus Group Discussions generated qualitative data. Multiple linear regression in excel was used to test the hypothesis.

Findings: The current study indicates that maximum number of ITNs is between five and six per household. Majority of households have used ITNs for over ten years. Preference for white ITNs was high at 52\%, rectangular nets $86.2 \%$ and double bed ITNs $100 \%$. Hypothesis test using multiple linear regression indicate that 3.3\% variation in use of ITNs is explained by colour, shape and size with a P-value of 0.85 . Since this statistic is greater than alpha 0.05 at $95 \%$ confidence level there is strong evidence not to reject the null hypothesis and conclude that ITN attributes do not significantly influence use of ITNs.

Unique contribution to theory, practice and policy: This study demonstrated that limits to growth system theory can be used to understand weaknesses of health promotion strategies. In practice housing standards must be integrated in health education activities for malaria prevention as they have been identified to be a limiting factor affecting use of ITNs.
\end{abstract}

Keywords: Product design attributes, Insecticide Treated Mosquito Nets, usage of ITNs. 
International Journal of Health, Medicine and Nursing Practice

ISSSN 2520- 0852 (Online)

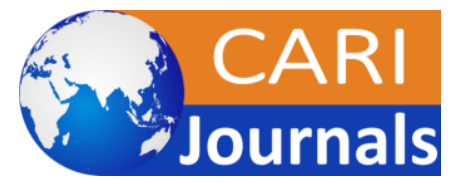

Vol.2, Issue No.1, pp 42 - 59, 2020

www.carijournals.org

\subsection{INTRODUCTION}

Insecticide Treated Mosquito Nets (ITNs) are the most recommended means for personal protection against mosquito vectors that transmit malaria. ITNs are made of cotton and polyester, Polyethylene, or Polyamide. For individuals to be protected they must sleep under an ITN every night. One way to increase ITN usage by individuals is to increase knowledge on importance of ITN use. In the recent past, extensive research regarding knowledge, attitudes and practices of ITNs have been conducted to find solutions to low ITN use. In Zambia knowledge levels on ITNs are above $60 \%$.

\subsection{Background}

Zambia adopted Insecticide Treated Mosquito Nets (ITNs) as an effective intervention for malaria prevention in 2001 (Freddie Masaninga, 2018). The effectiveness of ITNs is dependent on the coverage by households (Roll Back Malaria, 2005). This report explains that when coverage is high, even those members of the community that do not sleep under them also get protected from malaria One study conducted in Zambia proved that ITN does reduce prevalence of malaria (Jessie Pinchoff, 2015). Based on some of these empirical evidences, ITNs have been prioritized as a key intervention for protection from mosquito vectors that transmit malaria parasites to humans. To date over 9.5 million ITNs have been distributed to households in the Zamia (ZDHS, 2018). Further, this ZDHS report shows that over $72 \%$ of households possess at least one ITN with an average of 1.6 ITNs per household. Despite high ITN ownership, utilization rate is below $50 \%$. Extensive research on this topic has over the years focused on investigating knowledge gap on importance of sleeping under ITNs. In addition, even the Zambia national malaria communication strategy (207-2021) does not have an objective around product features or attributes and how they may influence use or non-use of ITNs. An understanding on attributes is significant in the sense that every product will have both negative and positive consequences which ultimately influences decisions to use or not use the product. This study therefore has been designed to investigate whether ITN product attributes in relation to shape, size and colour have influence on ITN use.

\subsection{Statement of the problem}

Utilization of Insecticide Treated Nets (ITNs) has been significantly very low for over a decade in Zambia. The Zambia Demographic and Health Survey reports of (ZDHS: 2007-2018) indicates that use of ITNs has been ranging between 28 to 48 percent. This will affect the malaria elimination program by 2030 as ITNs are among the key personal protection interventions. Secondly low utilization rates affect community herd protection because when few people sleep under ITNs there is less effect on reducing mosquito population in the community (Malaria Consortium, 2016). To address this problem, ITN awareness campaigns have been conducted country wide over the years resulting in an increase of knowledge levels of above $60 \%$ among Zambians (NMIS, 2015). Despite continued sensitization and awareness efforts, ITN use has not gone above $50 \%$. In other countries this has been attributed to none considerations for shape, size, designs and colour of ITNs Sande el tal; (2012). 
International Journal of Health, Medicine and Nursing Practice

ISSSN 2520- 0852 (Online)

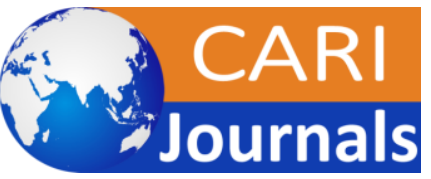

Vol.2, Issue No.1, pp 42 - 59, 2020

www.carijournals.org

\section{The Aim of the study}

The aim of the research was to understand from the study participants' account on whether ITN design attributes in terms of colour, size, shape does influence their decisions to use ITNs. The outcome of this study provides useful reference information on the importance of understanding systems thinking in designing and implementation of the national ITN communication strategies and development of communication materials.

\subsection{Objectives of the research}

The main objective of the study was to determine the levels of association between ITN attributes and use in order to contribute to the strategies used to promote ITNs. Below are specific objectives.

i. To determine the average number of ITNs owned per household.

ii. To examine the level of association between ITN attributes and use.

iii. To determine community level solutions to increase use of ITNs.

\subsection{Research questions}

The main research question was to investigate the association between ITN attributes and use. Below are specific questions.

i. What is the average number of ITNs per Household?

ii. What is the association between ITN attributes and use?

iii. What are the local solutions that can lead to improved use of ITNs?

\subsection{Hypotheses}

Ho: ITN attributes do not significantly influence use

Ha: ITN attributes do significantly influence use

\subsection{LITERATURE REVIEW}

\subsection{Theoretical review}

The current study was anchored on the Means-End Chain (MEC) theory. However, in order to have a broader view of the constructs in the problem, other theories such as the Reasoned Action Model of Consumer Preference (RAMCP), Diffusion of Innovations and limits to growth theories were reviewed.

\subsubsection{Means-End Chain (MEC) Theory}

The Means-End Chain theory was first introduced by Gutman and focused on qualitative in-depth understanding of consumer motives (Jusan, 2011). This theory postulates that the perceived consequences of product attributes influences product user decision. Conceptually, MEC views product users as goal-oriented and that they make decisions that most likely lead to desired outcomes (Costaa, 2004). Thus, in making these decisions, consumers make such judgements based on the consequential outcomes and perceived values of such consequences rather than attributes (Saadatfard, 2014). Figuratively the MEC theory is as shown in Figure 1 below shows a pictorial view of the variables in a MEC model starting with product attributes, consequences and values. 
International Journal of Health, Medicine and Nursing Practice

ISSSN 2520- 0852 (Online)

Vol.2, Issue No.1, pp 42 - 59, 2020

$\underline{\text { www.carijournals.org }}$

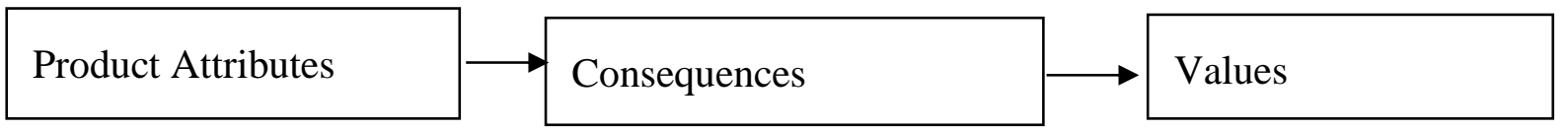

Figure 1: MEC Model

Source: (Jusan, 2011)

Attributes in Figure 1 above refer to concrete or abstract features of a product (Jusan, 2011). According to Jusan, the term 'concrete' refers to things that can be observed with our senses such as colour while 'abstracts' are expressions' such as feelings of hotness. These attributes directly cause some consequences negatively or positively. These are outcomes following use of a product such as itching while values are also abstract relating to enduring benefits or end state arising from use of a product. In relation to ITNs, the MEC model was used to explain consequences of ITN attributes and how users derive values of ITNs.

\subsubsection{Reasoned Action Model of Consumer Preference (RAMCP) Theory}

The theory of Reasoned Action original model was developed by Fishbein and Ajzen in 1975 (Sulehri, 2017). This theory assumes that the consumers' preference for a product is triggered when they are convinced that the product will perform the desired function as long as other members of society have approved it (Reid, Frischknecht and Papalambros, 2012). According to this theory, behavior is dependent on the intention, which is also dependent on the attitude and subjective norm (Simbolon, 2015). Figure 2 below shows how attitude toward act, subjective norm influences behavioral intention and ultimately behavior.

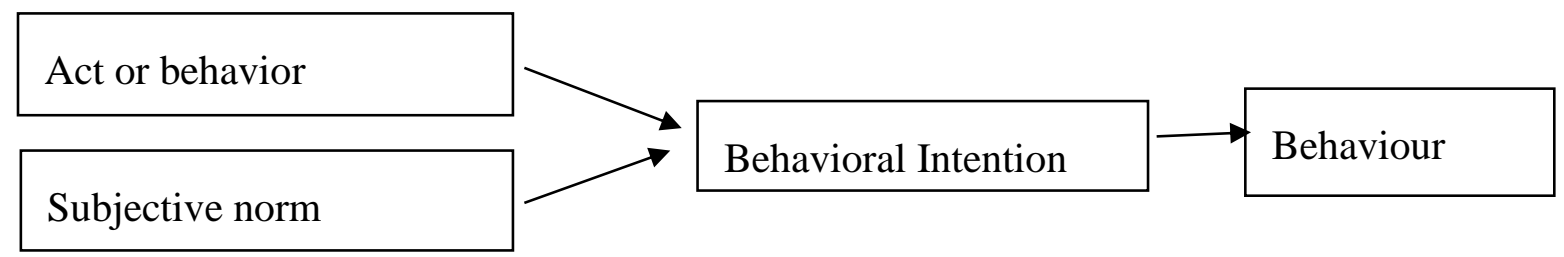

\section{Figure 2: RAMCP Model}

Source: (Sulehri, 2017).

Subjective norm refers to actions influenced by reference group/s in society that directly or indirectly influence behavior of an individual or more people. Act on the other hand is the attitude of product users while behavioral intention refers to consumers' or product users involved in the behavior (Simbolon, 2015). In relation to ITNs, the RAMCP was used to explain actions and subjective norms and how they influence behavior to use ITNs

\subsubsection{Diffusion of Innovation Theory}

The diffusion of innovations starts when one acquires knowledge (Rogers, 1971). According to Rodgers, this happens when the individual or other decision-making unit is exposed to the existence of an innovation and gains some understanding of how it functions. The major contribution of the diffusion of innovation theory in health communication is its emphasis on early 
audience segmentation (Schiavo, 2007). According to Schiavo, this theory supports health communication approaches that focuses messages on intended audiences and consideration of external conditions that are needed to achieve behavioral or social change.

Figure 3 below shows a diagrammatic view of the five phases of the diffusion of innovation model. It starts with knowledge, persuasion, decision, implementation and confirmation. Knowledge constitutes the characteristics of the decision making unit comprising socioeconomic characteristics, personality variables and communication behavior. Persuasion phase involves understanding perceived characteristics of the innovation such as relative advantage, compatibility, complexity, trial-ability and observability. These are expected to inform behavior whether to adopt the innovation or reject it resulting in confirmation phase. In relation to ITNs, this theory explains perception of ITN users and how they make such decisions.

Prior conditions

\section{Diffusion Model}

1 previous practice

2 felt needs/problems

3 Innovativeness

4 Norms of the social systems

Communication channels

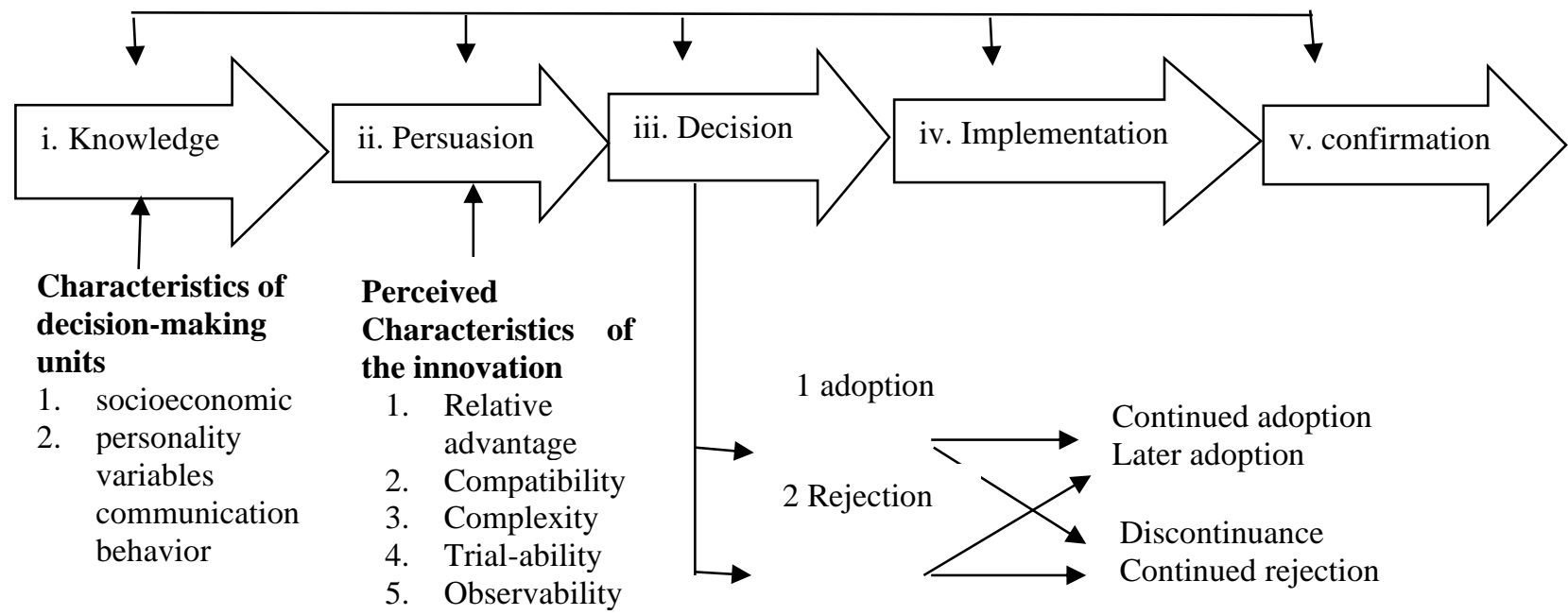

Figure 3: Diffusion model

Source: John E. Bowes, 1997

\subsubsection{Limits to growth theory}

The limits to growth theory postulates that results of an intervention always interacts with limiting factors that lead to a slowing action overtime (Bellinger, 2014). This theory claims that the limiting factor only comes into play when the results have reached a certain level. A real life example of this theory is related to the behavior of water in a bathtub that it will only run over till the water level gets to the overflow protection. At this point the speed of water flowing in (result) reduces. Figure 4 below shows limits to growth system archetype and how the results interacts with limiting factors. 


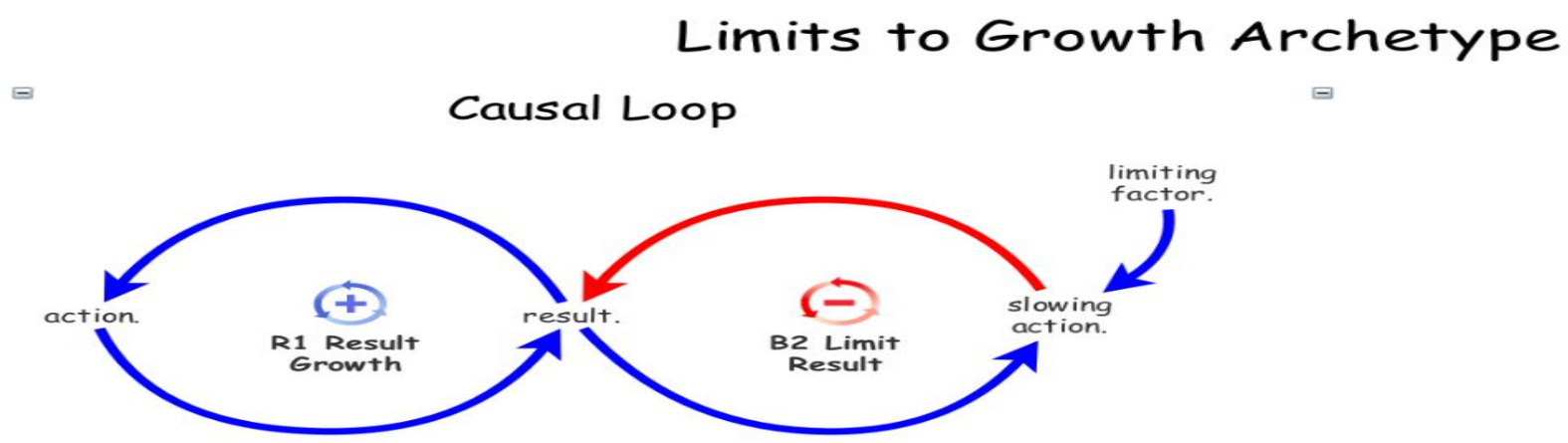

Figure 4: Limits to growth

Source: Berillinger 2014

Action in Figure 4 above is the intervention implemented which is reinforced with positive result (R1). By reinforcing means that as results grow the actor gets more motivated to repeat the interventions. However, limiting factors starts to interact with the results (B2) leading to some slowing action. The system behavior over time is depicted in figure 5 below. This demonstrates how the results gained over-time gets affected by limiting factors.

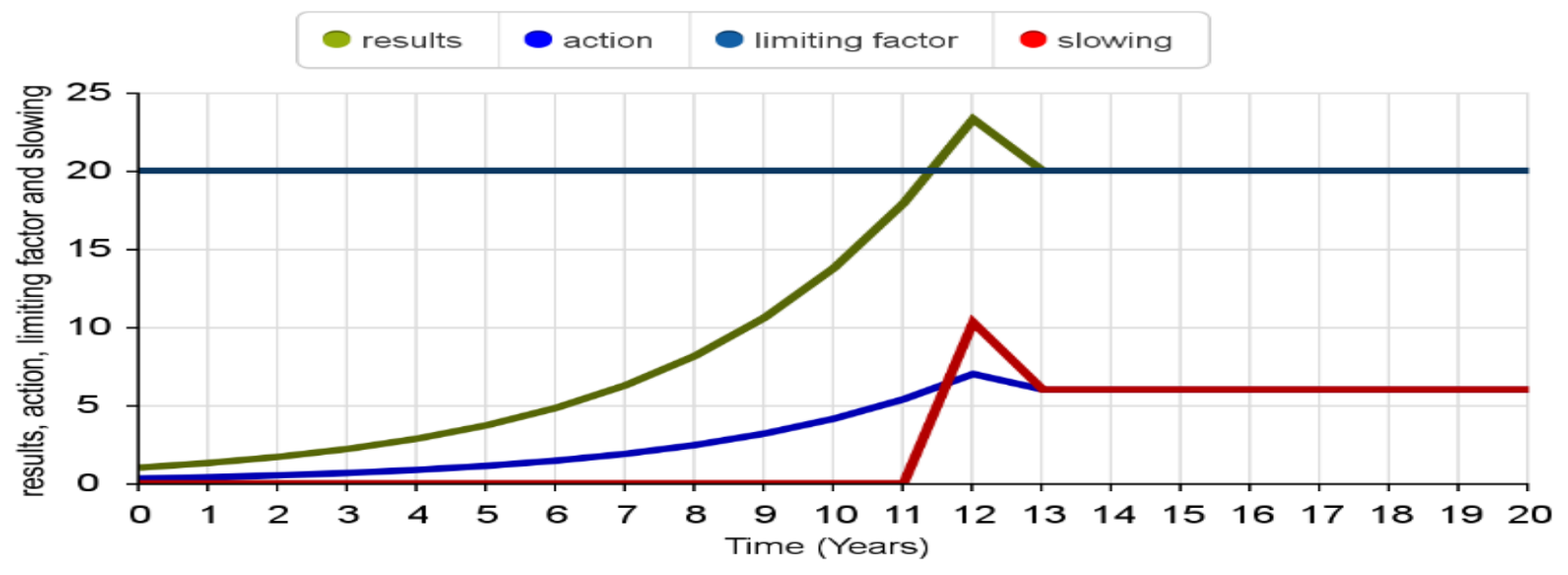

Figure 5: Limits to growth behavior

Source: Berllinger 2014

In Figure 5 above, the green line shows the results of action, blue line shows the action applied, red line shows the slowing action and the horizontal dark blue line indicates some limiting factors. This chart has helped to explain how efforts of $\mathrm{MOH}$ in ITN promotion interact with unknown factors affecting ITN usage.

\subsection{Literature review}

\subsubsection{Knowledge on Insecticide Treated Nets}

This study identifies several gaps in previous research in promotion of ITNs as highlighted by various researchers. First, much work has focused on knowledge and awareness about ITNs with 
International Journal of Health, Medicine and Nursing Practice

ISSSN 2520- 0852 (Online)

Vol.2, Issue No.1, pp 42 - 59, 2020

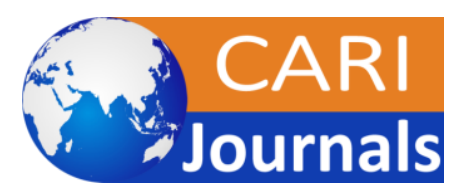

www.carijournals.org

no emphasis on ITN attributes [Ikeako el tal; (2017); Ijemba and Adogu; 2013; San el tal; (2013) and Ukibe el tal; (2014)]. Thus, knowledge on ITN as a product is quite limited. This present study investigated a sample of Neighborhood Health Committee members in Kafue district of Zambia with a focus on understanding availability of ITNs, preferences for ITN attributes: colour, shape and size.

\subsubsection{Attribute 1: Insecticide Treated Net colour}

The second gap from prior research is that there isn't much evidence on the relationship between the preference for colour and ITN use. Some studies have suggested that colour of nets might contribute to low ITN use (Ijemba and Adogu; 2013). Others have also revealed that white nets get dirty faster (Shafique and Smith; 2014; Njoroge el tal; (2009). This is among the first studies carried out to understand whether colour may influence use of an ITN.

\subsubsection{Attribute 2: Insecticide Treated Net Shape}

The third gap is that prior studies emphasized preference for rectangular or conical ITNs Njoroge el tal; (2009). The latter being liked because it has few points required to hang. On the other hand, the procedures for hanging rectangular nets are very cumbersome Sande el.tal; (2012). These studies for example did not bring out whether there are other confounding factors behind challenges of hanging nets. For instance, does housing design, materials used have any effect? This is among the first studies carried out to understand whether shape may influence use of an ITN.

\subsubsection{Attribute 2: Insecticide Treated Net Size}

The fourth gap is that little is explored by the previous researchers on ITN shape. The most wellknown factor is that majority prefer double or family size nets (Shafique and Smith, 2014). The value for this preference depends on whether the goal is to allow more people to sleep in the net or it's the need for space (Results for Development Institute, (2012). To understand whether ITN size matter in influencing use, there is need for research. This is among the first studies carried out to understand whether size may influence use of an ITN.

\subsubsection{ITN Attributes and consequences}

Consequences refers to outcomes following use of a product (Jusan, 2011). In terms of ITNs, some people have observed positive or negative consequences. Some of the positives include square fit of rectangular nets to sleeping beds/mats and less contact between user and mosquito net (Sande, 2012). However, safety related side effects associated with ITN use includes: hot/burning sensation, itching, dizziness, rashes, headache and smothering (Shafique, 2014). Similarly, itching or skin irritation was identified as one of the reasons respondents stopped using ITNs in Nigeria (Ukibe, 2014, Opondo, 2014). Another descriptive cross-sectional study by Ijemba (2013) in Nigeria revealed that about $88.3 \%$ of the respondents expressed feeling of suffocation and heat respectively as reasons for not using ITNs. The current research interrogated participants on their perceived experiential consequences using ITNs. 
International Journal of Health, Medicine and Nursing Practice

ISSSN 2520- 0852 (Online)

Vol.2, Issue No.1, pp 42 - 59, 2020

www.carijournals.org

\subsubsection{Conceptual Framework}

Figure 6 below shows the conceptual framework which was developed based on the theoretical frameworks and literature review. It is showing a prediction whether the preference for independent variables depicted by ITN attributes will influence behaviors to use ITNs.

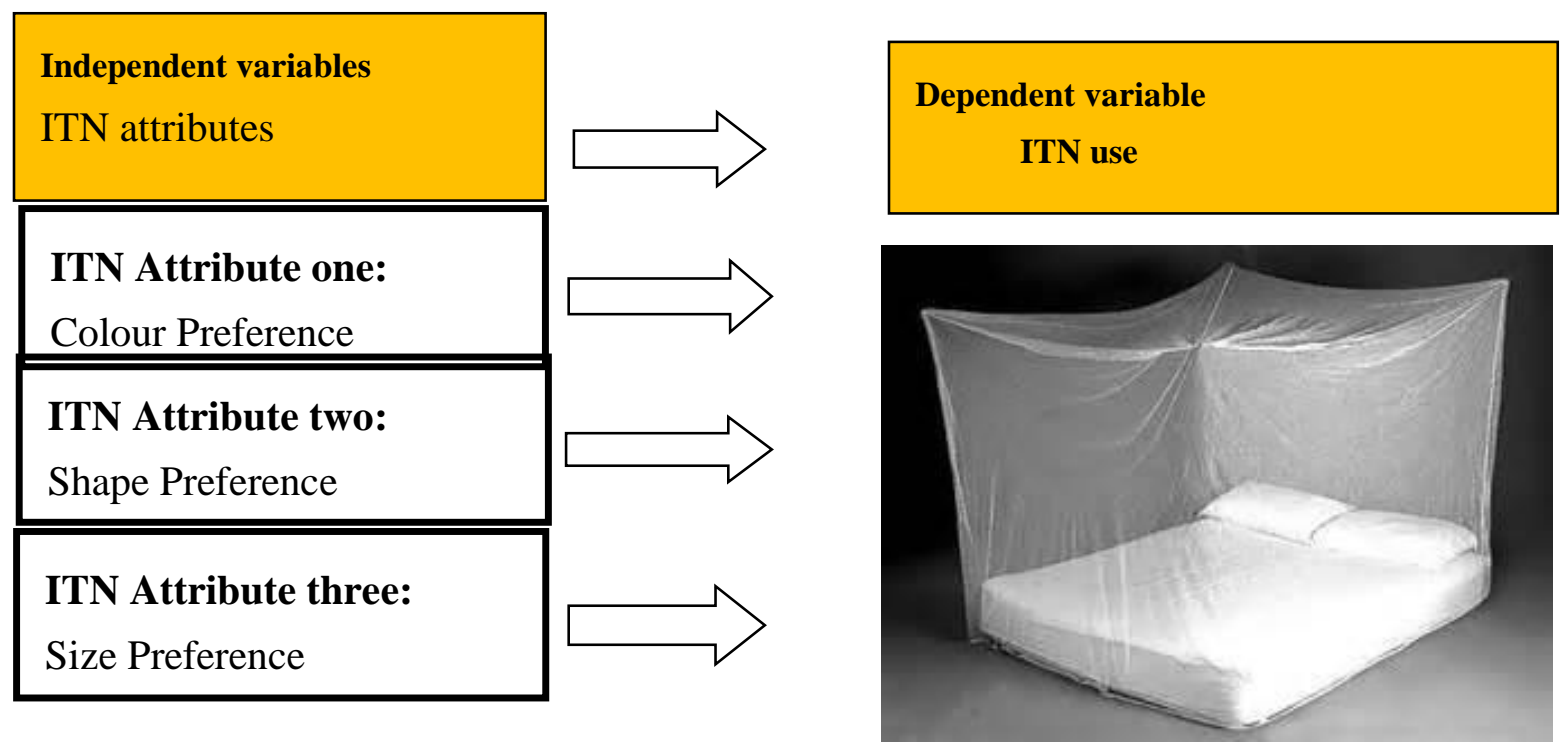

Figure 6: Concepual framework

Source: https://www.tauntonleisure.com/lifesystems-boxnet-mosquito-net-single.html

In Figure 6 above, independent variables are factors that when manipulated can have a direct effect on the decisions to use ITNs. For instance, if an individual is given an ITN of any colour, shape and size how will they respond to that? In the current study, a null hypothesis was that these independent factors do not significantly affect use of ITNs.

\subsection{METHODOLOGY}

\subsection{Study Design}

This study used mixed methods research design. It was anchored on both realist and nominalist ontology. The realism aspect influenced collection of data that can be observed and quantified using a questionnaire. This constituted the quantitative approach. The nominalist part was satisfied by collecting participants' views based on their social account using ITNs. This data was collected through focus Group Discussions (FGDs) and satisfied the qualitative aspect of the study.

\subsection{Study population}

The study population comprised all household heads from Neighborhood Health Committees NHCs of Nangongwe and Kafue Mission Health Centre catchment areas that had ITNs. The two facilities had a total of 300 households and were purposively selected by the District Health Office 
International Journal of Health, Medicine and Nursing Practice

ISSSN 2520- 0852 (Online)

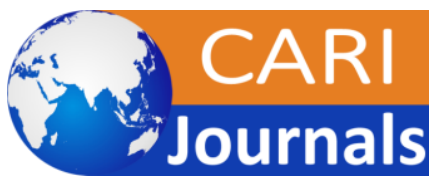

Vol.2, Issue No.1, pp 42 - 59, 2020

www.carijournals.org

(DHO) based on the number of ITNs distributed and mosquito density. From the two facilities, two Neighborhood Health Committee (NHCs) were randomly selected.

\subsection{Sampling}

A random sampling approach was used to select 30 households (HHs) from a total of $300 \mathrm{HHs}$ that had ITNs. Due to heavy rains, one HH was not reached hence sample size reduced to $29 \mathrm{HHs}$. Since houses are not built in ordered lines, the first house was randomly selected. After that the researcher adopted the meandering, snake movement style to pick houses randomly bearing in mind they should not be tool close to each.

\subsection{Data collection methods}

Questionnaires were used to collect quantitative data while a checklist was used to guide FGDs with NHCs. Questionnaires were used to collect respondent biographical data, ITN information. FGDs were used to understand why some HHs may not use ITNs and what local solutions can be used to increase ITN use.

\subsection{Quantitative Data analysis}

Quantitative data were analyzed using multiple linear regression using Microsoft excel to test the hypothesis that ITN design attributes do not influence use of ITNs. This was done using analysis of variance (ANOVA) and if the calculated p-value was less than alpha 0.05 at $95 \%$ confidence level, the null hypothesis was rejected and conclude that there is an association between preference for attributes and use.

\subsection{Definition and Measurement of variables}

- ITN use was measured using multiple regression to determine its association between ITN use and preference for colour, shape and size.

- ITN colour was measured as s percentage that preferred white, green, blue and any other ITN colour.

- ITN shape was measured as a percentage of households that preferred rectangular or conical ITN.

- ITN size was measured as a percentage of households that preferred single, three quarter or a double bed sized ITN.

\subsection{Qualitative Data analysis}

Qualitative data were analyzed using the Framework Approach to derive themes related to the research objectives. This was done in four key stages: -familiarization, constructing a thematic framework, indexing and mapping and interpretation

\subsection{Instrument validity and reliability}

A methods triangulation was utilized to ensure data of the same topic was captured using different methods. In this study questionnaires and focus group discussions were used to capture data and during analysis findings were cross checked in order to assure validity of the research. 
International Journal of Health, Medicine and Nursing Practice

ISSSN 2520- 0852 (Online)

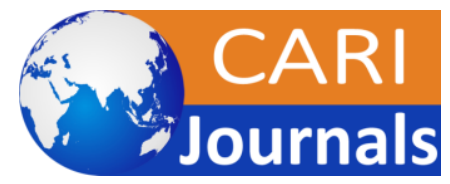

Vol.2, Issue No.1, pp 42 - 59, 2020

www.carijournals.org

\subsection{Ethical Considerations}

The researcher sought ethical clearance from the University of Zambia Directorate of Research and Graduate Studies (DRGS). During the data collection process, oral informed consent was obtained from the participant before the interview; the researcher disclosed all information that respondents were expected to know by reading the introductory letter in their hearing so that each participant understood. Based on this they were free to refuse or agree to participate in the study.

\subsection{Inclusion/exclusion criteria}

The following inclusion and exclusion criteria were applied in the selection of the respondents: Respondents who did not have an ITN were not be allowed to participate in the In-Depth Interviews (IDIs). Respondents who live very close to each other were not eligible to respond to questionnaires or and these also did not qualify to attend FGDs.

\subsection{RESEARCH FINDINGS}

\subsection{Respondent biographical data}

The minimum age for respondents was 16 for Kafue Mission and 40 years for Nangongwe. The maximum age was 67 and 83 years respectively for both areas. There were no outliers for Kafue Mission community less than 6 years and above 90 years while Nangongwe community had one respondent aged 83 years which was an outlier above the upper data bound of 71.75 years. Furthermore, majority of the respondents were female representing $69 \%$ while $31 \%$ were males. Out of these, majority of the respondents were married representing $66 \%$ followed by widows at $28 \%$ respectively.

\subsection{Ownership and utilization of Insecticide Treated Nets}

Majority of households in Kafue Mission community had two ITNs while those in Nangongwe had three to four ITNs. Out of these households, majority of HHs had used ITNs for over ten. The mean number of years was eight years. Of these, 25 out of 29 respondents representing $86.2 \%$ reported sleeping under the net always while only $13.7 \%$ reported sleeping in the ITN sometimes. This was measured using ordinal scale by asking respondents to choose how often they sleep under an ITN from the options: always, sometimes and never.

\subsection{Colour preference for Insecticide Treated Nets (ITNs).}

The findings in this study indicates that 15 out of 29 respondents representing $52 \%$ prefer white colour while $31 \%$ and $17.2 \%$ like blue and green ITNs respectively. Those who prefer white ITNs said it's because it brightens the bedroom, easy to see if its dirty and mosquitoes and other insects sitting on the net. Almost half of respondents prefer green or blue nets because they do not get dirty easily.

\subsection{Shape and size preference for Insecticide Treated Nets (ITN)}

This study has showed that 25 out of $29 \mathrm{HHs}$ representing $86.2 \%$ prefer rectangular nets while $13.7 \%$ said they like conical nets. Rectangular nets are liked because they fit bed size (59\%), do not allow contact with the skin, spacious, easy to hang. Respondents also observed some negative experiences that include: difficult to hang (13.7\%) and does ITNs not fit the bed size (3.4\%). In 
addition, 38\% of HHs like double bed net because they fit bed size very well, accommodate more people especially children because they are spacious. Other respondents however, observed that double size ITNs distributed by the Ministry of Health seem to be small as they have difficulties to hang them and does not fit the bed properly.

\subsection{Focus Group Discussions (FGDs)}

In order to triangulate the quantitative data, FGDs were held. Participants were asked to rate consistent use of ITNs by members of their community in a year on a scale 1 to 10 where one is the lowest level of ITN use and 10 being the highest level of ITN use.

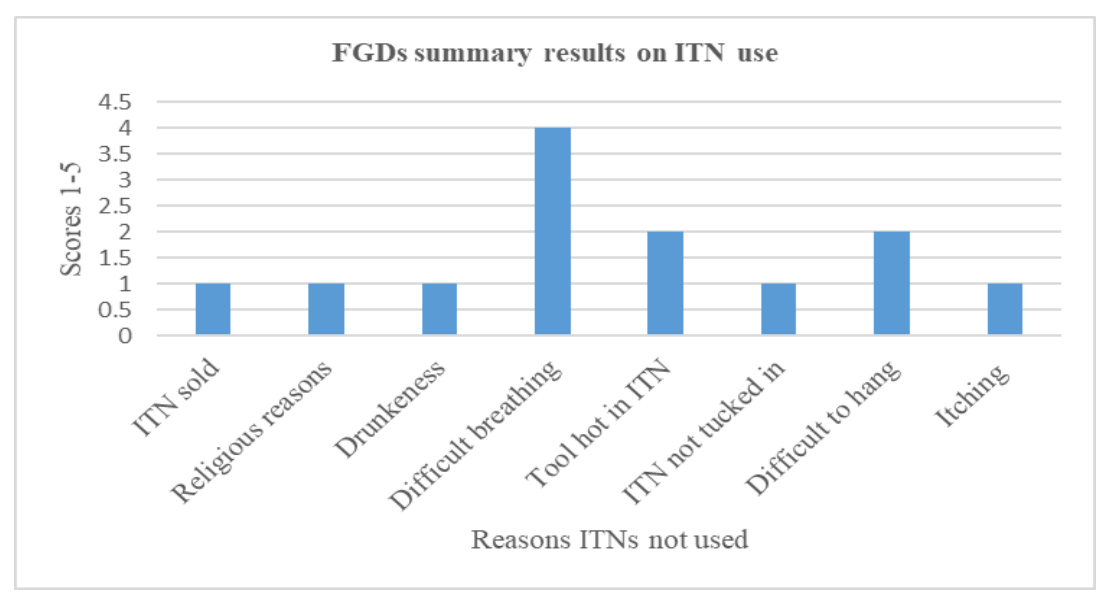

\section{Figure 7: Reasons ITN not used consistently}

Figure seven above indicates that of the households that do not use ITNs always, they experience difficulties to breath followed by feeling hotness and difficult to hang the net. Further, participants attributed these experiences to poorly constructed dwelling houses in most cases without windows that allow air flow into the house and weak materials that make hanging of the net difficult. Participants further suggested that in order to improve ITN use, dwelling houses must be constructed openable windows, adequate room space as well as continued health education on malaria prevention.

\subsection{Hypothesis testing}

Ho: ITN attributes do not significantly influence use

Ha: ITN attributes do significantly influence use

This Hypothesis was tested based on the data shown in table 4 below.

Table 8 below shows the regression analysis table. It shows the summary regression statistics, analysis of variance and coefficients 
International Journal of Health, Medicine and Nursing Practice

ISSSN 2520- 0852 (Online)

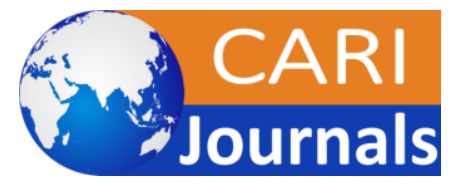

Vol.2, Issue No.1, pp 42 - 59, 2020

www.carijournals.org

SUMMARY OUTPUT

\begin{tabular}{lr}
\hline \multicolumn{2}{c}{ Regression Statistics } \\
\hline Mulfple R & 0.18165834 \\
R Square & 0.032999752 \\
Adjusted R Square & -0.093130715 \\
Siandard Error & 0.33483723 \\
Observafions & 27 \\
\hline
\end{tabular}

\begin{tabular}{lrrrrr} 
ANOVA & \multicolumn{1}{c}{ SS } & \multicolumn{1}{c}{ MS } & \multicolumn{1}{c}{$F$} & Significance $F$ \\
\hline \multicolumn{1}{l}{ Regression } & & 0.08799934 & 0.0293331 & 0.2616319 & 0.852279164 \\
Residual & 23 & 2.578667327 & 0.112116 & & \\
Total & 26 & 2.666666667 & & & \\
\hline
\end{tabular}

\begin{tabular}{lrrrlrrrr}
\hline & Coefficients & \multicolumn{1}{c}{ Standard Error } & \multicolumn{1}{c}{ Stat } & P-value & Lower 95\% & Upper 95\% & Lower 95.0\% & Upper 95.0\% \\
\hline Intercept & 1.18314804 & 0.187343919 & 6.31538 & $1.916 \mathrm{E}-06$ & 0.795597616 & 1.570698463 & 0.795597616 & 1.570698463 \\
Preference for size & 0 & 0 & 65535 & \#NUM! & 0 & 0 & 0 & 0 \\
Preference for shape & -0.133996489 & 0.159131575 & -0.8420484 & \#NUM! & -0.463185233 & 0.195192255 & -0.46318523 & 0.195192255 \\
Preference for colour & 0.053247513 & 0.103725284 & 0.5133513 & 0.6126018 & -0.161324585 & 0.267819612 & -0.16132459 & 0.267819612 \\
\hline
\end{tabular}

\section{Figure 8: ANOVA}

The coefficient of determination (R square) in table 2 above shows that $3.3 \%$ of the variation in use of ITNs is explained by ITN attributes: colour, shape and size. Furthermore, the analysis of variance on the same table also shows that the overall $\mathrm{P}$-value represented as significant $\mathrm{F}$ is 0.85 . Since this value is greater than alpha 0.05 at $95 \%$ confidence level, we have strong evidence not to reject the null hypothesis and conclude that ITN attributes do not significantly influence use of ITNs. Furthermore, the overall y intercept is 1.18 while individual attribute intercepts are zero meaning that for every individual that does not have any preference for ITN attributes, they will use an ITN.

\subsection{DISCUSSION}

\subsection{Ownership of Insecticide Treated Nets (ITNs)}

The results of the present research indicate that the majority of households have at least two nets. This result supports the ZDHS (2018) which confirmed that most households in Zambia have on average 1.6 nets. In the current study some households had over five nets. This means that at least three sleeping spaces can be covered as per ITN distribution criteria which targets to cover at least three sleeping spaces per household. The number of ITNs owned however, does not always translate into usage. The present study did not investigate further whether the number of nets or if each household had nets on each bed space would influence use of ITNs.

\subsection{Utilization of Insecticide Treated Nets (ITNs)}

In the current study, over $80 \%$ of respondents stated that they always sleep under an ITN. This however contradicted the outcome of focus group discussions conducted in the same community 
on why some people do not sleep under ITNs. Their argument was that most people do not always sleep under ITNs because they feel hot or do not breath properly inside a net. This outcome correlates with (Ijemba, 2013) who observed that some people experience suffocation when they sleep in the net. The implications of such expressions are that ownership of nets could be high but utilization rate is low because of such limiting factors. However, since this view was raised during focus group discussions, it has some level of subjectivity hence further study is recommended.

\subsection{Research results}

The result of the present study indicates that 3.3\% of the variation in use of ITNs is explained by ITN attributes: colour, shape and size. The current study has shown that over $50 \%$ of respondent prefer white nets though $80 \%$ of respondents said white nets get dirty fast. This result correlates with (Shafique, 2014; Njoroge el tal; 2009) who observed that white nets get easily get dirty. However, in the current study, some respondents prefer white nets because it's easy to see dirty, mosquitos and other insects sitting on the net. Despite these negative sentiments, colour was not identified as one of the reasons for not sleeping under an ITN.

In terms of shape and size of ITNs, the study showed that, rectangular nets were more preferred (80\%) because they easily fit on at least a double bed and can accommodate more people. This is contrary to the findings by Njoroge el tal; (2009) who observed that rectangular nets are not favored because they are difficult to hang than conical nets. In the current study, respondent had only rectangular nets. An interrogation was made to get their experiences using rectangular nets. Majority over $80 \%$ stated that these nets fits to bed squarely, are spacious, easy to hang and no skin contact as compared to conical nets. This result is well supported by the Mean End Chain (MEC) theory which posits that product attributes influences consequences and these in turn influence values and decision to use a product. Organizations promoting ITNs must consider incorporating positive experiences expressed in this paper as they design key messages for ITNs.

The implication of this result showed that there are other factors that influence ITN use. Based on this, a modified conceptual framework has been developed based on the other factors that were identified during focus group discussions.

\subsection{Modified conceptual framework}

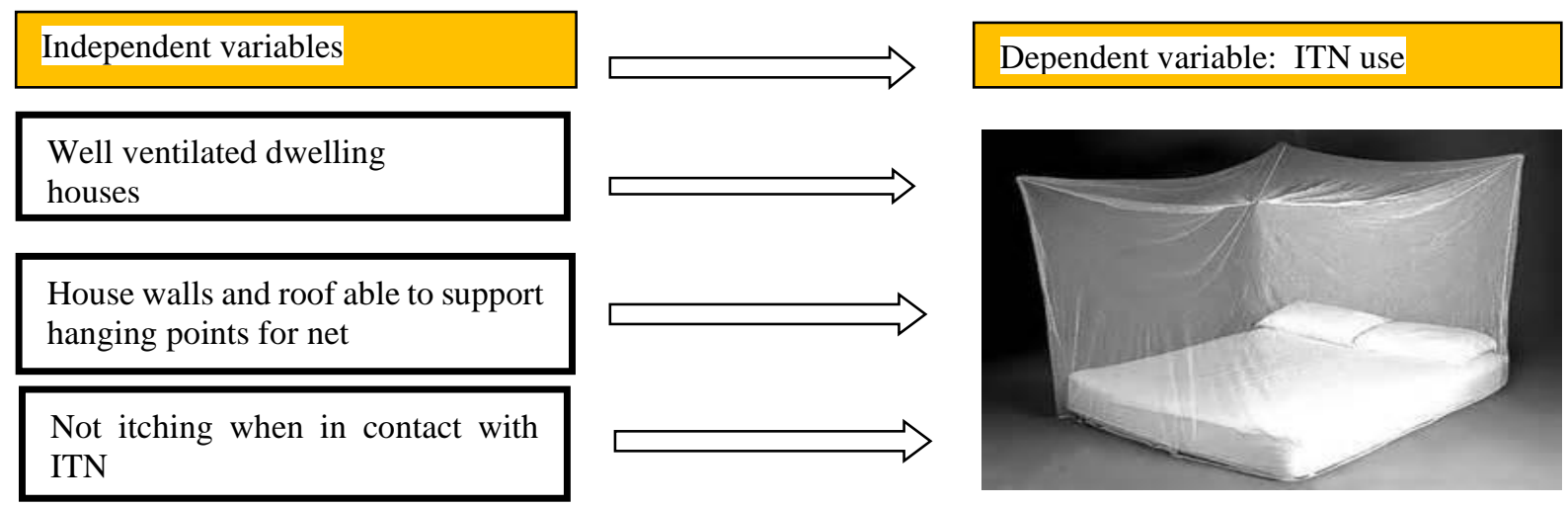

Figure 9: Modified conceptual framework

Source: https://www.tauntonleisure.com/lifesystems-boxnet-mosquito-net-single.html 
International Journal of Health, Medicine and Nursing Practice

ISSSN 2520- 0852 (Online)

Vol.2, Issue No.1, pp 42 - 59, 2020

www.carijournals.org

\subsection{Implications of results}

Data from ZDHS suggests that the Ministry of Health focus is to increase ITN use by creating awareness and mass distribution of ITNs. The fact that utilization rate is still below $50 \%$ after 20 years since ITNs were launched, the benefits could now be interacting with some limiting factors identified in this study. This outcome is clearly explained by the limits to growth theory which postulates that results of an intervention always interacts with limiting factors that lead to a slowing action overtime (Bellinger, 2014). This theory further claims that the limiting factors only comes into play when the results have reached a certain amount.

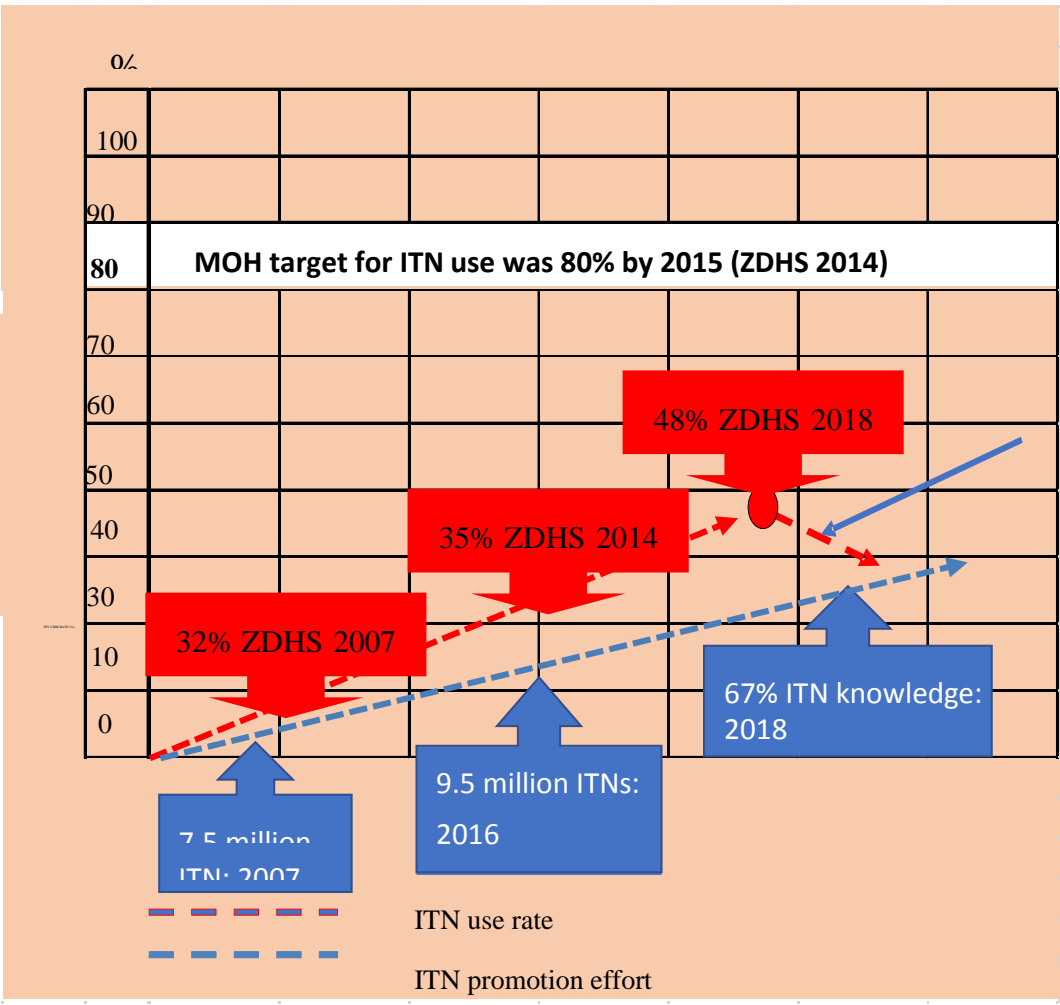

Drop in ITN use if limiting factors are not addressed

\section{Figure 10: Implications}

Figure 10 above indicate that ITN distribution has been increasing since 2007. At the same time knowledge on ITNs has been going up during the same time period. The MOH set a target of $80 \%$ ITN user rate by 2015 but only managed $48 \%$ as at 2018 . ITN user rates have been significantly very minimal between the period 2007, 2014 and 2018. This looks like ITN use has reached a plateau. This situation, as modelled through the limits to growth theory provides warning signals that if limiting factors relating to improved ventilation, room sized are not addressed, there is likelihood that ITN use may start to drop.

\subsection{Limitations of the study}

This study was more skewed to qualitative design. It focused on understanding subjective reality of the respondents hence a small sample size of households. Therefore, the results cannot be generalized but it has created an opportunity for future research to explore the factors identified leading to low ITN utilization. 


\subsection{Future research direction}

Based on the limitations of the current study, the following future research are recommended

- There is need to establish whether there is a relationship between housing standards, insecticides on netting material, social factors and use of ITNs.

- Association between integration of messages on attributes and behaviour to use ITNs

- The present study did not investigate further whether the number of nets or if each household had nets on each bed space would influence use of ITNs.

- The present study did not investigate further whether the number of years' households have used nets would influence use.

\subsection{Conclusion}

This present study concludes that ITN colour, shape and size do not influence use. Instead ventilation and size of dwelling houses have been identified to be closely linked to failure to use ITNs. However, the Ministry of Health and institutions developing ITN communication strategies cannot easily observe that housing ventilation is a limiting factor as this requires systems thinking approach lens in order to visualize how different factors surrounding a problem are interconnected as demonstrated using a limit to growth system architype. Based on this, it was observed that easy solutions such as creating awareness on ITN use are prioritized for implementation which creates a tendency of repeating even when it has no impact to reduce the problem. Therefore, if the Ministry of Health does not reflect on the implications highlighted in this study, ITNs user rates are likely to start dropping. Local solutions as suggested by participants in this study to intensify education to community members so that they build dwelling houses with adequate window spaces that allow airflow and reduce hotness and difficult breathing experienced when they sleep under ITNs require institutional support. The current study recommendations are as under:

\subsection{Recommendations}

This study discovered a weak link between design of dwelling houses and use of ITNs and therefore recommends as follows:

- The MOH must re-design the ITN communication strategy to begin focusing on incorporating housing standards into malaria prevention programs by integrating key stakeholders such as local government

- Health promoting agencies must design messages that will amplify the positive experiences of ITN colour, shape and size attributes and address negative feelings about ITNs.

- The MOH should consider engaging other stakeholders to ensure dwelling houses meets ventilation standards as these have negative impact on end malaria efforts and general health. 
International Journal of Health, Medicine and Nursing Practice

ISSSN 2520- 0852 (Online)

Vol.2, Issue No.1, pp 42 - 59, 2020

www.carijournals.org

\section{REFERENCES}

Adogu, P. O., \& Ijemba, C. (2013). Insecticide treated nets possession and utilization among pregnant women in Enugu Nigeria: a descriptive cross-sectional study. Journal of Natural Sciences Research, 3(15), 40-47.

Anderson, D. R., Sweeney, D. J., Williams, T. A., Camm, J. D., \& Cochran, J. J. (2016). Statistics for business \& economics. Nelson Education.

Ango, U. M., Anka, A. M., Awosan, K. J., Oche, O. M., Yakubu, A., \& Raji, M. O. Awareness, perception, and utilization of insecticides treated nets and intermittent preventive treatment of malaria among pregnant women in Sokoto, Nigeria. Asian Pacific Journal of Health Sciences 5(1), $64-69$.

Bellinger, G. (2014, June 20). Retrieved from https://www.insightmaker.com/article/24288/Limits-to-Growth-Archetype

Costa, A. D. A., Dekker, M., \& Jongen, W. M. F. (2004). An overview of means-end theory: potential application in consumer-oriented food product design. Trends in food science \& technology, 15(7-8), 403-415.

Ikeako, L. C. A. E., CAzuike, E. C., \& Njelita, I. A. (2017). Insecticide Treated Nets: Perception and Practice among Pregnant Women Accessing Antenatal Services at a Tertiary Hospital in Awka, Nigeria. MOJ Public Health, 5(4), 00135.

JHU. (2012). Uganda Culture of Mosquito Net Use Study, s.1.: Johns Hopkins Bloomberg School of Public Health Center for Communication Programs.

Kotler, P. (1999). Marketing management: The millennium edition (Vol. 199). Upper Saddle River, NJ: Prentice Hall.

M Rogers, E. (1971). Diffusion of Innovations Third Edition, published by the Free PressA Division of Macmillan Publishing Co., Inc, New York.

M. Omole, T., Ogunfowokan, O., \& Moses, A. (2017). Use of Insecticide-treated Net and Malaria Parasitemia in Under-fives at National Hospital Abuja. International Journal of TROPICAL DISEASE \& Health, 23(3), 1-17. https://doi.org/10.9734/IJTDH/2017/33848

Njoroge, F. K., Kimani, V. M., Ongore, D., \& Akwale, W. S. (2009). Use of insecticide treated bed nets among pregnant women in Kilifi District, Kenya. East African medical journal, 86(7).

Opondo, B., Oluoch, E. O., Anjejo, D., \& Otieno-Ayayo, Z. N. (2014). Efficacy, Efficiency And Impact Of Long-Lasting Insecticidal Nets Utilization And In Door Residual Spraying: A Survey Of Rural Kaptumo Location, Nandi County, Kenya. Baraton Interdisciplinary Reseach Journal 4, pp. 35-51.

Reid, T. N., Frischknecht, B. D., \& Papalambros, P. Y. (2012). Perceptual attributes in product design: Fuel economy and silhouette-based perceived environmental friendliness tradeoffs in automotive vehicle design. Journal of mechanical design, 134(4). 
International Journal of Health, Medicine and Nursing Practice

ISSSN 2520- 0852 (Online)

Vol.2, Issue No.1, pp 42 - 59, 2020

www.carijournals.org

Renata Schiavo 2007. Health Communication From Theory to Practice: Published by Jossey-Bass A Wiley Imprint 989 Market Street, San Francisco. www.josseybass.com.

Sande, S., Jagals, P., Mupeta, B., \& Chadambuka, A. (2012). An investigation of the use of rectangular insecticide-treated nets for malaria control in Chipinge District, Zimbabwe: a descriptive study. The Pan African Medical Journal, 13.

Simbolon, S. (2015). Application of theory of reasoned action in predicting the consumer behavior to buy the Toyota Avanza Veloz at PT. Putera Auto Perkasa Medan. Journal of Asian Scientific Research, 5(7), 357.

Soe, Z., \& Shwe, W. H. (2013). Knowledge, Attitude and Practice on Insecticide Treated Nets in Myanmar. International Journal of Collaborative Research on Internal Medicine \& Public Health, 5(6), 0-0.

Sulehri, N. A., \& Ahmed, M. (2017). Theory of reasoned action and retail agglomerations buying behavior for urban consumers. The Business \& Management Review, 9(2), 263-266.

Ukibe, S. N., Ikeako, L. C., Mbanugo, J. I., Obi-Okaro, A. C., \& Ukibe, N. R. (2014). Knowledge, Attitude and Practices of Pregnant Women concerning the use of Insecticide Treated Bed Nets (ITNs) in Anambra State, South-east Nigeria. Journal of Applied Medical Sciences, 3(1), 15-22.

Ulrich, K. T. (2003). Product design and development. Tata McGraw-Hill Education.

USAID-Results for Development Institute, (2012). Value for money in LLIN specifications guidance ensuring the hightest value for money in LLIN procurement by balacing cost with end user program benefits, Washington: Results for Development Institute.

Watiro, A. H., \& Awoke, W. (2016). Insecticide-treated net ownership and utilization and factors that influence their use in Itang, Gambella region, Ethiopia: cross-sectional study. Risk management and healthcare policy, 9, 101.

Wharton, A., \& Agreement, C. (2014). Qualitative Study to Assess Consumer Preferences and Barriers to Use of Long-Lasting Insecticidal nets (LLINs) in Myanmar.

WHO. (2003). Information on factory pre-tested nets and conventional treatment of coloured mosquito nets, Geneva: World Health Organization.

WHO. (2017). A framework for malaria elimination, Geneva: WHO.

Zachariah, Z. B., \& Jusan, M. B. M. (2011). Means-end chain model framework for measuring housing environment choice behavior.Journal of Civil Engineering and Architecture, 5(6).

Zambia NMES. (2014). Zambia National Malaria Communication Strategy, Lusaka: National Malaria Elimination Strategy. Available at: https://www.nmec.org.zm/s/NationalCommunication-Strategy-for-Malaria-Elimination.pdf

Zambia NMES. (2015). Zambia National Malaria Indicator Survey, Lusaka: NMEC.

Zambia NMESP , 2017-2021. National Malaria Elimination Strategic Plan 2017-2021, Lusaka: NMEC. Available at: 
International Journal of Health, Medicine and Nursing Practice

ISSSN 2520- 0852 (Online)

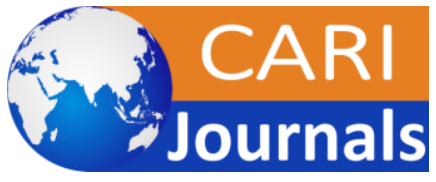

Vol.2, Issue No.1, pp 42 - 59, 2020

www.carijournals.org

https://static1.squarespace.com/static/58d002f017bffcf99fe21889/t/5b28d7f1575d1ff0942

dbce1/1529403401067/National+Malaria+Elimination+Strategic+Plan+2017-

Final_PRINT.pdf

ZDHS. (2007). Zambia Demographic and Health Survey, Lusaka: Central Statistical Office. https://dhsprogram.com/pubs/pdf/FR361/FR361.pdf

ZDHS. (2014). Zambia Demographic and Health Survey, Lusaka: Central Statistical Office (CSO). https://www.dhsprogram.com/pubs/pdf/FR304/FR304.pdf

ZDHS. (2018). Zambia Demographic and Health Survey. Lusaka: Central Statistical Office. https://dhsprogram.com/pubs/pdf/FR361/FR361.pdf 